OPEN ACCESS

Renzo Bianchi,

University of Neuchâtel,

Switzerland

Reviewed by:

Michael Herzog,

École Polytechnique Fédérale de

Lausanne, Switzerland

Wolfgang Tschacher,

University of Bern, Switzerland

*Correspondence:

Michael P. Hengartner michaelpascal.hengartner@

zhaw.ch

Specialty section:

This article was submitted

to Psychopathology,

a section of the journal

Frontiers in Psychiatry

Received: 05 April 2017 Accepted: 23 May 2017

Published: 07 June 2017

Citation:

Hengartner MP and Lehmann SN (2017) Why Psychiatric Research Must Abandon Traditional Diagnostic

Classification and Adopt a

Fully Dimensional Scope: Two

Solutions to a Persistent Problem.

Front. Psychiatry 8:101.

doi: 10.3389/fpsyt.2017.00101

\section{Why Psychiatric Research Must Abandon Traditional Diagnostic Classification and Adopt a Fully Dimensional Scope: Two Solutions to a Persistent Problem}

\author{
Michael P. Hengartner ${ }^{1 *}$ and Sandrine N. Lehmann ${ }^{2}$ \\ ${ }^{1}$ Department of Applied Psychology, Zurich University of Applied Sciences, Zurich, Switzerland, ${ }^{2}$ Department of Psychiatry, \\ Psychotherapy and Psychosomatics, University Hospital of Psychiatry, Zurich, Switzerland
}

Keywords: research, psychiatric nosology, diagnosis, psychopathology, DSM, ICD, hierarchical taxonomy of psychopathology, research domain criteria

Psychiatric research is still strongly influenced by its major classification schemes, the DSM-5 (1) and ICD-10 (2). According to these diagnostic classification systems, psychiatric nosology is construed based on multinomial taxonomic distinctions, i.e., a set of putatively independent disorder entities that are either present or absent based on polythetic-categorical criteria. Many published papers in psychiatry use these dichotomous diagnoses as the main unit of analysis. However, as it stands, these classification systems have major limitations that substantially impede scientific progress (3-5). In the following, we will detail why DSM/ICD-based approaches to the study of mental disorders are inadequate ways to address psychopathology. We will outline the major limitations of categorical psychiatric diagnoses as implemented in the current classification systems, and then we will introduce two promising approaches that were designed to circumvent these caveats.

\section{DSM AND ICD DO NOT ADEQUATELY ASSESS PSYCHOPATHOLOGY}

No single psychiatric diagnosis has reliably shown to represent a discrete taxa, i.e., clearly demarcated disorder entities that reliably delineate disorders from each other (between-disorder boundary) and normality from disease (within-disorder boundary) $(6-10)$. A specific example is provided below. For comprehensive reviews, see, for instance, Ref. $(3,11,12)$. Most evidence suggests that psychopathology is fully dimensional by nature, but it is worth noting that there is also some inconclusive support for a few discrete taxa $(7,13)$. Unfortunately, current psychiatric nosology as defined by DSM/ICD does not define distinct natural entities, and diagnoses are neither mutually exclusive nor exhaustive $(11,14)$. Therefore, boundaries between distinct diagnoses are fuzzy, there is significant heterogeneity within diagnoses, many patients are classified with vague "not otherwisespecified" diagnoses, and comorbidity between putatively independent disorders is excessive $(3,4,12)$. As it stands, psychopathology is not organized according to the DSM/ICD scheme, irrespective of whether assessed categorical or dimensional (15-19). Even the reliability of psychiatric diagnoses, once a milestone in the development of psychiatric nosology, turned out to be fairly modest or even questionable for various disorders $(20,21)$. Fortunately, there is an easy and straightforward solution to that problem, as dimensional representations of mental disorders have shown to substantially improve reliability and validity above and beyond categorical measures (22). In accordance, many experts in psychiatric nosology and psychopathology now claim that our 
current classification systems have significantly impeded further progress in etiological research and treatment development (3, 23-25).

In the following, we will briefly recapitulate some of the most pressing limitations underlying current nosology using the example of the 10 DSM-5 personality disorder (PD) diagnoses, as experts in $\mathrm{PD}$ research have repeatedly emphasized that these diagnostic categories are neither reliable nor valid (26-29). More specific, the 10 diagnoses listed in DSM-5 are arbitrary distinctions without empirical foundation. There is compelling evidence that PD not otherwise specified is among the most prevalent PD diagnoses despite being conceptualized as a residual category (30), which stresses the inadequate coverage of diagnostic categories. Phenotypically and genetically, personality pathology collapses into 3-5 distinct factors, but not into the 10 DSM PD diagnoses (31-34). These findings stress the problem of missing between-disorder boundaries. Contrary to prevailing diagnostic criteria, these factors are not dichotomous syndromes that are distinct from normal personality, but dimensional continua that co-vary substantially with normative personality traits $(33,35,36)$. These findings stress the issue of missing within-disorder boundaries (i.e., distinction between normal and pathological). In consequence, although both DSM and ICD state that PD are enduring conditions, the categorical diagnoses that they determine are not stable at all, which stands in sharp contrast to the high stability of both normative personality and dimensional PD traits in the very same persons (37-39).

\section{DIMENSIONAL MODELS OF PSYCHOPATHOLOGY}

\section{Hierarchical Taxonomy of Psychopathology (HiTOP)}

The HiTOP was developed by an independent consortium of psychopathology researchers (24). This program was a result of a long-lasting dissatisfaction with the current classification systems and their inability to adequately model the structure of psychopathology. Its major objective is to provide an empirically based, fully dimensional organization of psychopathology by subjecting current diagnoses, syndromes, and symptoms to multivariate factor-analytic procedures. Recently, various authors have significantly advanced insights in the quantitative hierarchical structure of psychopathology [(15-17, 19, 40-42); for reviews, see Ref. $(43,44)]$. HiTOP posits that psychopathology is hierarchically structured, i.e., symptoms/signs (level 1) are nested within syndromes/traits (level 2) and the latter are nested within factors (level 3). Broad spectra are situated on top of the hierarchy (level 4). By this means, superordinate domains can account for the interdependence of lower-order structures such as correlated personality traits and psychopathological syndromes. Broad spectra at level 4 encompass internalizing pathology, externalizing pathology (comprising disinhibited and antagonistic), thought disorder (i.e., psychosis spectrum disorders), and detachment (i.e., pathological introversion). Subfactors of the internalizing spectrum at level 3 include sexual problems, eating pathology, fear, and distress, whereas subfactors of the externalizing spectrum include substance abuse and antisocial behavior. For more details, see Ref. (24). A pioneering innovation of the HiTOP is its incorporation of personality traits into the structure of psychopathology. This is an important step toward an evidence-based psychiatric nosology, as a compelling body of evidence has confirmed that personality substantially impacts on the occurrence, re-occurrence, and persistence of psychopathology (45-48), comorbidity between mental disorders (49-52), and, most importantly, on the liability to and course of broad internalizing and externalizing spectra (19, 53-55), and the general factor of psychopathology (40, 56-58). Though not its main target, HiTOP can also advance research on genetic vulnerabilities and genetic markers, as the proposed hierarchical structure and correlations between its dimensions appear to reflect common genetic liabilities (58-63). It is further posited that HiTOP dimensions may show clearer and stronger links to neurobiological marker, that they can effectively capture illness course, that they account for functional impairment related to psychopathology, and that they may predict efficacy and generalizability of treatments (24).

\section{Research Domain Criteria (RDoC)}

The RDoC program was initiated by the National Institute of Mental Health (NIMH) due to the organization's discontent with the current psychiatric classification system (64). As psychiatric diagnoses do not represent valid disease entities, the NIMH decided to allocate its resources away from the DSM and toward genetic, neuroimaging, and cognitive sciences to design a diagnostic scheme based on neurobiological and behavioral phenotypes. Despite substantial efforts during the last two decades, genetic research and the neurosciences have largely failed to detect any reliable marker that could be applied for clinical tests to aid diagnosis and prognosis $(23,65)$. This failure is untenable for a specialty that contemplates a future within the clinical neurosciences (66), and lack of progress was in part attributed to the constraints imposed by the invalid DSM/ICD-based diagnostic categories (3). Therefore, RDoC set out to develop a classification system that would advance insights into the neurobiology of mental disorders. This system adopts a fully dimensional and translational scheme of mental disorders, i.e., it views psychopathology in terms of deviations in fundamental functional systems. In contrast to the standard DSM/ICD top-down approach, which defines a mental disorder on the basis of signs and symptoms and then seeks to uncover the etiopathology underlying these disorders, RDoC encourages a bottom-up approach. This strategy involves that researcher define the normal distribution of a given trait or characteristic, that they examine the brain system that implements this function, and then which factors may account for dysregulation or dysfunction in these systems resulting in psychopathological symptoms and syndromes (65). The project directs research toward five neurobiological domains, specifically, negative valence systems, positive valence systems, cognitive systems, systems for social processes, and arousal/modulatory systems. These domains are divided into several units of analysis, including genes, circuits, physiology, and behavior. Each domain further contains several constructs. For instance, the negative valence systems domain involves the constructs of acute threat 
(fear), potential threat (anxiety), sustained threat, loss, and frustrative non-reward $(23,65)$. Distinct pathophysiological mechanisms subsumed under the same fuzzy diagnostic DSM/ ICD-based category are seen by the pharmaceutical industry as a major cause of the low-response rate of psychiatric drugs (67). $\mathrm{RDoC}$ therefore constitutes a promising biological approach that could help to circumvent the problems associated with diagnostic heterogeneity and, accordingly, the lack of pathophysiological specificity within and between psychiatric diagnoses. As stated by Cuthbert and Insel (23), "As yet, the field of mental disorders research lags badly behind the rest of medicine in moving toward precision medicine" (p. 3). As a result, various pharmaceutical companies have withdrawn their investments from research on new psychiatric drugs (68). The authors of RDoC hence legitimately claim that this neurobiological classification system may substantially improve etiological research, promote the development of new treatments, and ease the detection of genetic and neurobiological markers for application in diagnostic clinical tests $(23,64,65)$. Finally, it is worth noting that RDoC has been criticized $(69,70)$, but a detailed account is beyond the scope of this opinion paper.

\section{CONCLUSION AND OUTLOOK}

HiTOP and RDoC are recently developed dimensional frameworks aimed at replacing the systematically flawed classification systems of DSM-5 and ICD-10 for research purposes. These two pioneering approaches are best seen as complementary rather than as competing systems. Both approaches have in common that they adopt a hierarchical, fully dimensional scheme. However, while HiTOP focuses exclusively on psychopathological symptoms, syndromes, and broad phenomenological domains, $\mathrm{RDoC}$ is largely aimed at examining genetic and neurobiological units of analysis. Therefore, RDoC holds particular promise for advancing neurobiological research relevant to psychopathology, while HiTOP is mainly concerned with restructuring psychiatric nosology by providing an empirical organization of psychopathology (24). Psychiatric research into the epidemiology of mental disorders has long struggled to accurately describe the development and course of psychopathology and how risk factors relate to the cooccurrence and stability of mental disorders due to the field's predominant focus on inadequate, discrete diagnostic taxa $(12,44)$. With respect to

\section{REFERENCES}

1. American Psychiatric Association. Diagnostic and Statistical Manual of Mental Disorders DSM-5. Washington, DC: American Psychiatric Association (2013).

2. World Health Organization. International Classification of Diseases ICD-10. 10th ed. Geneva: World Health Organization (1992).

3. Hyman SE. The diagnosis of mental disorders: the problem of reification. Annu Rev Clin Psychol (2010) 6:155-79. doi:10.1146/annurev.clinpsy.3.022806. 091532

4. Krueger RF, Bezdjian S. Enhancing research and treatment of mental disorders with dimensional concepts: toward DSM-V and ICD-11. World Psychiatry (2009) 8:3-6. doi:10.1002/j.2051-5545.2009.tb00197.x

5. Lilienfeld SO. DSM-5: centripetal scientific and centrifugal antiscientific forces. Clin Psychol Sci Pract (2014) 21:269-79. doi:10.1111/Cpsp.12075 neurobiological research, the inherent limitations of the heterogeneous and fuzzy DSM/ICD diagnoses were recently disclosed by a comprehensive meta-analysis of functional neuroimaging studies in patients with unipolar depression (71). In this work, it was demonstrated that no single pattern of aberrant brain activation consistently replicates across cognitive and emotional processing experiments. These inconsistencies may in part relate to inadequate statistical procedures and other methodological biases $(72,73)$, but heterogeneous clinical populations based on distinct neurobiological etiopathologies and symptom profiles are also major contributors (71). Psychiatric research must, therefore, abandon traditional DSM/ICD nosology and adopt valid and evidence-based dimensional schemes if it wants to advance insights into the etiology of mental disorders. Finally, and worthy of note, some have suggested that DSM/ICD-based diagnoses may have clinical utility despite their poor validity (11, 17). However, how could a psychiatric nosology have clinical utility when it impedes the development of efficacious treatments and clinical tests, an improved understanding of etiology and a reliable prediction of illness course $(26,27,66)$ ? Moreover, critics of dimensional approaches typically stress that clinical practice requires binary diagnoses. However, at this stage, both HiTOP and $\mathrm{RDoC}$ are merely research programs, so diagnostic entities are not necessary $(3,23,24)$. Once dimensional concepts are ready for implementation in clinical practice, one could easily transform dimensional scores into categorical distinctions, just like we treat intellectual disabilities or how Peter Tyrer and the ICD-11 PD work group conceptualized the continuum of PD severity, comprising no personality disturbance, personality difficulties, mild PD, moderate PD, and severe PD (28). Such a categorical gradation considers that psychopathology is dimensional by nature but at the same time allows for making diagnoses in order to identify people who require treatment or disability benefits.

\section{AUTHOR CONTRIBUTIONS}

$\mathrm{MH}$ drafted the manuscript. SL contributed in writing and critical revision.

\section{FUNDING}

No funding was obtained for this work.

6. Hankin BL, Fraley RC, Lahey BB, Waldman ID. Is depression best viewed as a continuum or discrete category? A taxometric analysis of childhood and adolescent depression in a population-based sample. J Abnorm Psychol (2005) 114:96-110. doi:10.1037/0021-843X.114.1.96

7. Haslam N, Holland E, Kuppens P. Categories versus dimensions in personality and psychopathology: a quantitative review of taxometric research. Psychol Med (2012) 42:903-20. doi:10.1017/S0033291711001966

8. Markon KE, Krueger RF. Categorical and continuous models of liability to externalizing disorders: a direct comparison in NESARC. Arch Gen Psychiatry (2005) 62:1352-9. doi:10.1001/archpsyc.62.12.1352

9. Walton KE, Ormel J, Krueger RF. The dimensional nature of externalizing behaviors in adolescence: evidence from a direct comparison of categorical, dimensional, and hybrid models. J Abnorm Child Psychol (2011) 39:553-61. doi:10.1007/s10802-010-9478-y 
10. Wright AG, Krueger RF, Hobbs MJ, Markon KE, Eaton NR, Slade T. The structure of psychopathology: toward an expanded quantitative empirical model. J Abnorm Psychol (2013) 122:281-94. doi:10.1037/a0030133

11. Kendell R, Jablensky A. Distinguishing between the validity and utility of psychiatric diagnoses. Am J Psychiatry (2003) 160:4-12. doi:10.1176/appi. ajp.160.1.4

12. Widiger TA, Samuel DB. Diagnostic categories or dimensions? A question for the diagnostic and statistical manual of mental disorders - fifth edition. J Abnorm Psychol (2005) 114:494-504. doi:10.1037/0021-843X.114.4.494

13. Coghill D, Sonuga-Barke EJ. Annual research review: categories versus dimensions in the classification and conceptualisation of child and adolescent mental disorders - implications of recent empirical study. JChild Psychol Psychiatry (2012) 53:469-89. doi:10.1111/j.1469-7610.2011.02511.x

14. Jablensky A. Psychiatric classifications: validity and utility. World Psychiatry (2016) 15:26-31. doi:10.1002/wps.20284

15. Kotov R, Ruggero CJ, Krueger RF, Watson D, Yuan Q, Zimmerman M. New dimensions in the quantitative classification of mental illness. Arch Gen Psychiatry (2011) 68:1003-11. doi:10.1001/archgenpsychiatry.2011.107

16. Krueger RF, Caspi A, Moffitt TE, Silva PA. The structure and stability of common mental disorders (DSM-III-R): a longitudinal-epidemiological study. J Abnorm Psychol (1998) 107:216-27. doi:10.1037/0021-843X. 107.2.216

17. Markon KE. Modeling psychopathology structure: a symptom-level analysis of axis I and II disorders. Psychol Med (2010) 40:273-88. doi:10.1017/ S0033291709990183

18. Rhebergen $D$, van der Steenstraten IM, Sunderland M, de Graaf R, Ten Have M, Lamers F, et al. An examination of generalized anxiety disorder and dysthymic disorder by latent class analysis. Psychol Med (2014) 44:1701-12. doi:10.1017/ S0033291713002225

19. Wright AG, Simms LJ. A metastructural model of mental disorders and pathological personality traits. Psychol Med (2015) 45:2309-19. doi:10.1017/ S0033291715000252

20. Chmielewski M, Clark LA, Bagby RM, Watson D. Method matters: understanding diagnostic reliability in DSM-IV and DSM-5. J Abnorm Psychol (2015) 124:764-9. doi:10.1037/abn0000069

21. Regier DA, Narrow WE, Clarke DE, Kraemer HC, Kuramoto SJ, Kuhl EA, et al. DSM-5 field trials in the United States and Canada, part II: test-retest reliability of selected categorical diagnoses. Am J Psychiatry (2013) 170:59-70. doi:10.1176/appi.ajp.2012.12070999

22. Markon KE, Chmielewski M, Miller CJ. The reliability and validity of discrete and continuous measures of psychopathology: a quantitative review. Psychol Bull (2011) 137:856-79. doi:10.1037/a0023678

23. Cuthbert BN, Insel TR. Toward the future of psychiatric diagnosis: the seven pillars of RDoC. BMC Med (2013) 11:126. doi:10.1186/1741-7015-11-126

24. Kotov R, Krueger RF, Watson D, Achenbach TM, Althoff RR, Bagby RM, et al. The hierarchical taxonomy of psychopathology (HiTOP): a dimensional alternative to traditional nosologies. J Abnorm Psychol (2017) 126(4):454-77. doi: $10.1037 / \mathrm{abn} 0000258$

25. Watson D, Clark LA. Clinical diagnosis at the crossroads. Clin Psychol Sci Pract (2006) 13:210-5. doi:10.1111/j.1468-2850.2006.00026.x

26. Clark LA. Assessment and diagnosis of personality disorder: perennial issues and an emerging reconceptualization. Annu Rev Psychol (2007) 58:227-57. doi:10.1146/annurev.psych.57.102904.190200

27. Farmer RF. Issues in the assessment and conceptualization of personality disorders. Clin Psychol Rev (2000) 20:823-51. doi:10.1016/S0272-7358(99) 00014-8

28. Tyrer P, Reed GM, Crawford MJ. Classification, assessment, prevalence, and effect of personality disorder. Lancet (2015) 385:717-26. doi:10.1016/ S0140-6736(14)61995-4

29. Widiger TA, Trull TJ. Plate tectonics in the classification of personality disorder: shifting to a dimensional model. Am Psychol (2007) 62:71-83. doi:10.1037/0003-066X.62.2.71

30. Verheul R, Widiger TA. A meta-analysis of the prevalence and usage of the personality disorder not otherwise specified (PDNOS) diagnosis. J Pers Disord (2004) 18:309-19. doi:10.1521/pedi.18.4.309.40350

31. Kendler KS, Aggen SH, Czajkowski N, Roysamb E, Tambs K, Torgersen S, et al. The structure of genetic and environmental risk factors for DSM-IV personality disorders: a multivariate twin study. Arch Gen Psychiatry (2008) 65:1438-46. doi:10.1001/archpsyc.65.12.1438
32. Livesley WJ, Jang KL, Vernon PA. Phenotypic and genetic structure of traits delineating personality disorder. Arch Gen Psychiatry (1998) 55:941-8. doi:10.1001/archpsyc.55.10.941

33. O'Connor BP. A search for consensus on the dimensional structure of personality disorders. J Clin Psychol (2005) 61:323-45. doi:10.1002/jclp.20017

34. Widiger TA, Livesley WJ, Clark LA. An integrative dimensional classification of personality disorder. Psychol Assess (2009) 21:243-55. doi:10.1037/ a0016606

35. Hengartner MP, Ajdacic-Gross V, Rodgers S, Muller M, Rossler W. The joint structure of normal and pathological personality: further evidence for a dimensional model. Compr Psychiatry (2014) 55:667-74. doi:10.1016/j. comppsych.2013.10.011

36. Samuel DB, Simms LJ, Clark LA, Livesley WJ, Widiger TA. An item response theory integration of normal and abnormal personality scales. Personal Disord (2010) 1:5-21. doi:10.1037/a0018136

37. Clark LA. Stability and change in personality disorder. Curr Dir Psychol Sci (2009) 18:27-31. doi:10.1111/j.1467-8721.2009.01600.x

38. Gunderson JG, Stout RL, McGlashan TH, Shea MT, Morey LC, Grilo CM, et al. Ten-year course of borderline personality disorder: psychopathology and function from the collaborative longitudinal personality disorders study. Arch Gen Psychiatry (2011) 68:827-37. doi:10.1001/archgenpsychiatry.2011.37

39. Morey LC, Hopwood CJ. Stability and change in personality disorders. Annu Rev Clin Psychol (2013) 9:499-528. doi:10.1146/annurev-clinpsy-050212185637

40. Caspi A, Houts RM, Belsky DW, Goldman-Mellor SJ, Harrington H, Israel S, et al. The p factor: one general psychopathology factor in the structure of psychiatric disorders? Clin Psychol Sci (2014) 2:119-37. doi:10.1177/ 2167702613497473

41. Lahey BB, Applegate B, Hakes JK, Zald DH, Hariri AR, Rathouz PJ. Is there a general factor of prevalent psychopathology during adulthood? J Abnorm Psychol (2012) 121:971-7. doi:10.1037/a0028355

42. Vollebergh WA, Iedema J, Bijl RV, de Graaf R, Smit F, Ormel J. The structure and stability of common mental disorders: the NEMESIS study. Arch Gen Psychiatry (2001) 58:597-603. doi:10.1001/archpsyc.58.6.597

43. Eaton NR, Rodriguez-Seijas C, Carragher N, Krueger RF. Transdiagnostic factors of psychopathology and substance use disorders: a review. Soc Psychiatry Psychiatr Epidemiol (2015) 50:171-82. doi:10.1007/s00127-014-1001-2

44. Krueger RF, Markon KE. Reinterpreting comorbidity: a model-based approach to understanding and classifying psychopathology. Annu Rev Clin Psychol (2006) 2:111-33. doi:10.1146/annurev.clinpsy.2.022305.095213

45. Brown TA. Temporal course and structural relationships among dimensions of temperament and DSM-IV anxiety and mood disorder constructs. J Abnorm Psychol (2007) 116:313-28. doi:10.1037/0021-843X.116.2.313

46. Hengartner MP, Ajdacic-Gross V, Wyss C, Angst J, Rossler W. Relationship between personality and psychopathology in a longitudinal community study: a test of the predisposition model. Psychol Med (2016) 46:1693-705. doi:10.1017/S0033291716000210

47. Krueger RF. Personality traits in late adolescence predict mental disorders in early adulthood: a prospective-epidemiological study. J Pers (1999) 67:39-65. doi:10.1111/1467-6494.00047

48. Wilson S, Vaidyanathan U, Miller MB, McGue M, Iacono WG. Premorbid risk factors for major depressive disorder: are they associated with early onset and recurrent course? Dev Psychopathol (2014) 26:1477-93. doi:10.1017/ S0954579414001151

49. Hengartner MP, Kawohl W, Haker H, Rossler W, Ajdacic-Gross V. Big five personality traits may inform public health policy and preventive medicine: evidence from a cross-sectional and a prospective longitudinal epidemiologic study in a Swiss community. J Psychosom Res (2016) 84:44-51. doi:10.1016/j. jpsychores.2016.03.012

50. Hengartner MP, Tyrer P, Ajdacic-Gross V, Angst J, Rossler W. Articulation and testing of a personality-centred model of psychopathology: evidence from a longitudinal community study over 30 years. Eur Arch Psychiatry Clin Neurosci (2017). doi:10.1007/s00406-017-0796-8

51. Khan AA, Jacobson KC, Gardner CO, Prescott CA, Kendler KS. Personality and comorbidity of common psychiatric disorders. Br J Psychiatry (2005) 186:190-6. doi:10.1192/bjp.186.3.190

52. Zinbarg RE, Mineka S, Bobova L, Craske MG, Vrshek-Schallhorn S, Griffith JW, et al. Testing a hierarchical model of neuroticism and its cognitive facets: latent structure and prospective prediction of first onsets of anxiety and 
unipolar mood disorders during 3 years in late adolescence. Clin Psychol Sci (2016) 4:805-24. doi:10.1177/2167702615618162

53. Conway CC, Craske MG, Zinbarg RE, Mineka S. Pathological personality traits and the naturalistic course of internalizing disorders among high-risk young adults. Depress Anxiety (2016) 33:84-93. doi:10.1002/da.22404

54. Griffith JW, Zinbarg RE, Craske MG, Mineka S, Rose RD, Waters AM, et al. Neuroticism as a common dimension in the internalizing disorders. Psychol Med (2010) 40:1125-36. doi:10.1017/S0033291709991449

55. Walton KE, Krueger RF, Elkins I, D’Accordo C, McGue M, Iacono WG. Personality traits predict the developmental course of externalizing: a fourwave longitudinal study spanning age 17 to age 29. J Pers (2016) 85(3):364-75. doi:10.1111/jopy.12245

56. Castellanos-Ryan N, Briere FN, O'Leary-Barrett M, Banaschewski T, Bokde A, Bromberg U, et al. The structure of psychopathology in adolescence and its common personality and cognitive correlates. J Abnorm Psychol (2016) 125:1039-52. doi:10.1037/abn0000193

57. Hankin BL, Davis EP, Snyder H, Young JF, Glynn LM, Sandman CA. Temperament factors and dimensional, latent bifactor models of child psychopathology: transdiagnostic and specific associations in two youth samples. Psychiatry Res (2017) 252:139-46. doi:10.1016/j.psychres.2017.02.061

58. Tackett JL, Lahey BB, van Hulle C, Waldman I, Krueger RF, Rathouz PJ. Common genetic influences on negative emotionality and a general psychopathology factor in childhood and adolescence. JAbnorm Psychol (2013) 122:1142-53. doi:10.1037/a0034151

59. Hettema JM, Neale MC, Myers JM, Prescott CA, Kendler KS. A populationbased twin study of the relationship between neuroticism and internalizing disorders. Am J Psychiatry (2006) 163:857-64. doi:10.1176/appi.ajp.163.5.857

60. Hicks BM, Krueger RF, Iacono WG, McGue M, Patrick CJ. Family transmission and heritability of externalizing disorders: a twin-family study. Arch Gen Psychiatry (2004) 61:922-8. doi:10.1001/archpsyc.61.9.922

61. Kendler KS, Aggen SH, Knudsen GP, Roysamb E, Neale MC, ReichbornKjennerud T. The structure of genetic and environmental risk factors for syndromal and subsyndromal common DSM-IV axis I and all axis II disorders. Am J Psychiatry (2011) 168:29-39. doi:10.1176/appi.ajp.2010.10030340

62. Kendler KS, Prescott CA, Myers J, Neale MC. The structure of genetic and environmental risk factors for common psychiatric and substance use disorders in men and women. Arch Gen Psychiatry (2003) 60:929-37. doi:10.1001/archpsyc.60.9.929

63. Lahey BB, Van Hulle CA, Singh AL, Waldman ID, Rathouz PJ. Higher-order genetic and environmental structure of prevalent forms of child and adolescent psychopathology. Arch Gen Psychiatry (2011) 68:181-9. doi:10.1001/ archgenpsychiatry.2010.192
64. Insel T, Cuthbert B, Garvey M, Heinssen R, Pine DS, Quinn K, et al. Research domain criteria $(\mathrm{RDoC})$ : toward a new classification framework for research on mental disorders. Am J Psychiatry (2010) 167:748-51. doi:10.1176/appi. ajp.2010.09091379

65. Cuthbert BN. The RDoC framework: facilitating transition from ICD/DSM to dimensional approaches that integrate neuroscience and psychopathology. World Psychiatry (2014) 13:28-35. doi:10.1002/wps.20087

66. Reynolds CF III, Lewis DA, Detre T, Schatzberg AF, Kupfer DJ. The future of psychiatry as clinical neuroscience. Acad Med (2009) 84:446-50. doi:10.1097/ ACM.0b013e31819a8052

67. Wong EH, Yocca F, Smith MA, Lee CM. Challenges and opportunities for drug discovery in psychiatric disorders: the drug hunters' perspective. Int J Neuropsychopharmacol (2010) 13:1269-84. doi:10.1017/S1461145710000866

68. Miller G. Is pharma running out of brainy ideas? Science (2010) 329:502-4. doi:10.1126/science.329.5991.502

69. Lilienfeld SO. The research domain criteria (RDoC): an analysis of methodological and conceptual challenges. Behav Res Ther (2014) 62:129-39. doi:10.1016/j.brat.2014.07.019

70. Weinberger DR, Glick ID, Klein DF. Whither research domain criteria (RDoC)? The good, the bad, and the ugly. JAMA Psychiatry (2015) 72:1161-2. doi:10.1001/jamapsychiatry.2015.1743

71. Muller VI, Cieslik EC, Serbanescu I, Laird AR, Fox PT, Eickhoff SB. Altered brain activity in unipolar depression revisited: meta-analyses of neuroimaging studies. JAMA Psychiatry (2017) 74:47-55. doi:10.1001/jamapsychiatry. 2016.2783

72. Button KS, Ioannidis JP, Mokrysz C, Nosek BA, Flint J, Robinson ES, et al. Power failure: why small sample size undermines the reliability of neuroscience. Nat Rev Neurosci (2013) 14:365-76. doi:10.1038/nrn3475

73. Eklund A, Nichols TE, Knutsson H. Cluster failure: why fMRI inferences for spatial extent have inflated false-positive rates. Proc Natl Acad Sci U S A (2016) 113:7900-5. doi:10.1073/pnas.1602413113

Conflict of Interest Statement: The authors declare that the research was conducted in the absence of any commercial or financial relationships that could be construed as a potential conflict of interest.

Copyright $\odot 2017$ Hengartner and Lehmann. This is an open-access article distributed under the terms of the Creative Commons Attribution License (CC BY). The use, distribution or reproduction in other forums is permitted, provided the original author(s) or licensor are credited and that the original publication in this journal is cited, in accordance with accepted academic practice. No use, distribution or reproduction is permitted which does not comply with these terms. 